\title{
Disciplinary Differences in the Uptake of a Learning Management System: A Case of a South African Historically Disadvantaged Institution
}

\section{Phumla Hlengiwe Shamase}

https://orcid.org/0000-0001-5412-8091

Mangosuthu University of Technology

pumlas@mut.ac.za

\section{Abstract}

The provision of a Learning Management System (LMS) for use in distributed, blended or open distance e-learning as a management tool has become a basic standard requirement in higher learning institutions globally. Many students and lecturers use an LMS in support of innovative and engaged teaching and learning, both inside and outside the classroom-whether blended or open leaning. However, many academics choose not to make use of the institutional LMS. This is the specific issue that this study addresses, with a particular focus on the role played by disciplinary differences in the uptake of an LMS. The research question guiding the study is thus: To what extent do disciplinary differences affect the uptake of an LMS? The research study drew on Legitimation Code Theory, a sociological theory that explains the knowledge principles underpinning practices, in this case, the practice of the uptake (or nonuptake) of an institutional LMS. The study made use of quantitative data collection and data analysis methods, drawing on the institutional LMS activity data. The study found that there was a significant relationship between the disciplines and LMS uptake. However, the study also found a number of unexpected exceptions, where the nature of the discipline did not seem to impact uptake or non-uptake. The contribution that the study makes is to show the significant role that the academics' home discipline plays in LMS uptake.

Keywords: Learning Management Systems; disciplinary differences and affinities

\section{Introduction}

Alias and Zainuddin $(2005,28)$ and Bousbahi and Alrazgan $(2015,1)$ define a Learning Management System (LMS) or Course Management System (CMS) or Virtual Learning Environment (VLE) as web-based technology used in planning, implementation and assessment of a specific learning process, while generating related reports for the users.

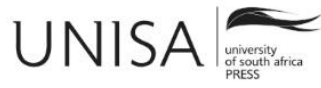




\section{Shamase}

The use of LMS dates as far back as the 1960s, only to be popularised by the advent of the Internet nowadays (Rhode et al. 2017, 69). Today, LMS is used in a distributed, blended or open distance e-learning as a management tool that has become standard practice and a requirement in many universities, both in South Africa and internationally (Dintoe 2018, 14; Van Barneveld, Arnold, and Campbell 2012, 1).

There is an expectation that courses will have an online presence, whether due to coercion or forced adoption by authorities or by the willing participation of lecturers. Therefore, students can access learning materials, course notes, presentations, assessments and so forth to support their learning through various online platforms (Oliver 2002). On the other hand, many lecturers feel that the use of LMS is indispensable to their teaching, and they make regular and creative use of the technological affordances (Chai, Koh, and Tsai 2010, 13). Motivation, computer anxiety and organisational support are salient factors in the adoption process of LMS by faculties (Bousbahi and Alrazgan 2015, 2). Faculties often design programmes that disregard the adoption or refusal of LMS for teaching and learning (Gautreau 2011, 1). Day and Loyd $(2007,22)$ highlight a shift in focus amongst users from the inherent technological properties to the opportunities for enhanced learning provided by an LMS.

However, the use of LMS supports the instructional process, therefore enhancing a student-centred teaching and learning process (Gautreau 2011, 2). Conole and Dyke $(2004,12)$ explain that in order to facilitate the shift from technical mastery to enhanced teaching practice, an LMS should be simple and straightforward to use, but have allowances for customisation so that the teacher retains autonomy of the pedagogy and knowledge content. In this way, lecturers can feel involved in the design of the learning platform, feel at ease with technology, and in turn possibly increase the LMS uptake (Koehler and Mishra 2005, 32). Despite the many positive reports of experiences with a number of LMS platforms, there are still many subjects that do not have an online presence across faculties (Koehler and Mishra 2009, 9). Therefore, the focus of this study is to investigate the disciplinary makeup that influences the uptake of LMS in the institution.

\section{Problem Statement}

There is considerable research to show that the appropriate use of an LMS can enhance the quality of teaching and student learning (Dintoe 2018, 14). However, Wichadee $(2015,53)$ identifies four inhibiting factors to the uptake of LMS: attitude towards LMS; perceived ease of use; perceived usefulness; and actual use. Literature also points to a perceived increase in workload that comes with the use of LMS as another factor identified by lecturers (Fathema and Sutton 2013, 20).

Another observation made from literature is that when there is uneven uptake or rejection of LMS across an institution, it can cause conditions of unfairness and disadvantage, resulting in some subjects seeing improved throughput rates, and others 


\section{Shamase}

experiencing challenges, including attrition and failure (Campbell, DeBlois, and Oblinger 2007, 42).

The uptake of educational technologies has been seen as a proxy for university teaching that is engaged, up-to-date and concerned with meeting students' varying needs (Chai et al. 2010, 13). On the other hand, students expect the LMS to be engaging and stimulating to make the learning process appealing and innovative (Winn 2002, 14). The problem that this present study addresses, is hypothesised as to how the general uptake of educational technology, in the form of an institutional LMS by lecturers, might not be related to their disciplines and fields.

The problem is significant in that understanding the reasons underlying the uptake can help e-learning trainers and managers to better plan the support of academics in terms of training and technical support. The teaching and learning management unit at the institution can use such valuable information for development purposes for the short and long term in order to achieve institutional goals. Albeit the lack of incentive or penalty from the use of LMS, faculties are still encouraged to use the LMS more effectively in their teaching and learning activities.

While there are many possible reasons why academics choose to or choose not to make use of an institutional LMS, the particular focus of this study is the role that disciplinary differences and affinities play with regard to the uptake of educational technology such as the LMS. The research question that guides this study is thus: To what extent do disciplinary differences affect the uptake and use of LMS? That answers two subquestions of the study:

a) Active subjects on LMS from departments of the faculties at the institution.

b) Disciplinary characteristics of the subjects subscribed in terms of classification according to: disciplines and fields underlined by Science, Technology, Engineering and Mathematics (STEM) disciplines and fields, and those that are underpinned by the Humanities, Arts and Social Sciences (HASS); as well as BOTH, a combination of STEM and HASS.

\section{Literature Review: The Uptake of Educational Technology}

There have been a number of studies on the uptake/non-uptake of educational technologies in higher education that point to the many factors that impact the uptake of such technologies, including: 1) institutional factors; 2) technical factors; 3) pedagogical factors; 4) instructional design factors; 5) lecturer factors; and 6) student factors (Fresen 2011, 11). Several studies identify "lecturer factors" to be the main barriers to uptake, in particular the time required in learning how to use web-based technologies and develop appropriate materials, the lack of training and support, and the continuing time requirements associated with using and monitoring web-based technologies in teaching (Pajo and Wallace 2001, 16). Studies have also found 


\section{Shamase}

"perceived self-efficacy" and facilitating conditions such as "faculty attitude" to be key predicting factors for the uptake of an LMS. Fewer studies report on the importance of an institutional strategy targeted at providing sufficient resources and guidance for effective implementation (e.g., King and Boyatt 2015, 46) and of system functionality (Pajo and Wallace 2001, 16).

Fathema, Shannon, and Ross $(2015,11)$ propose an extended Technology Acceptance Model (TMA) in determining users' technology acceptance behaviours, which suggests that both "lecturer factors" and "disciplinary factors"- that is, the extent to which the academic's home discipline is compatible with information and communication technology (ICT) - play a role in the uptake of educational technology. The Technological Pedagogical Content Knowledge (TPCK) model similarly proposes the identification of disciplinary or content knowledge and teacher or "lecturer factors" (in particular their understanding of e-pedagogy contributing to uptake and appropriate usage of educational technologies (Angeli and Valanides 2009, 52). Conole and Dyke $(2004,12)$ argue that ICTs have particular features, related to their disciplinary nature and having been developed in a technical field, that could support or mitigate against their uptake in particular disciplines and fields. Developing this idea further, Howard and Maton $(2011,19)$ suggest that the successful integration of ICT across a curriculum has to take into account the discipline-specific features, both of the educational technology and of the discipline or field that it is supporting.

\section{Context for Study}

The site chosen for this study was a historically disadvantaged institution (HDI) that mainly serves students from disadvantaged socio-economic backgrounds. There were a number of criteria for site selection in this study. Firstly, the university had to offer both HASS and STEM disciplines in order that the disciplinary differences could be compared. The second selection criterion was that the university needed to have a functioning LMS and reasonable connectivity. Thirdly, there had to be training and ongoing support for all the academic staff available. The fourth selection criterion was that while LMS adoption and use were encouraged and supported by the institution, the choice of whether or not to use the LMS was voluntary, with neither institutional incentives nor penalties. The blackboard seemed to be preferred by academic staff and was also supported by institutional authorities. Finally, it was important that the institution represented a majority of the previously disadvantaged population so that the benefits accruing from the research activities and findings would be in service of this community. The above criteria were intended to facilitate the investigation into the role played by disciplinary differences in their affiliation to LMS.

\section{Conceptual and Theoretical Frameworks}

The study which directed this article drew on Legitimation Code Theory (LCT); a sociological framework that seeks to identify the knowledge structures underpinning practice. The theory forms the basis of empirical research to understand organising 


\section{Shamase}

principles of knowledge practice across institutional and disciplinary maps of education. Among five dimensions of the theory that exist, this study focused on only one, namely semantics: the meaning of words, phrases or text. In part, this means that the extent to which meaning relates to context. The dimension was measured by strength along a continuum, e.g., strong (+) or weak (-). This can be interpreted as the stronger (+) the semantic, the more meaning is dependent on the context; the weaker the semantic, the less dependent it is on its context (Howard and Maton 2014, 19; Maton 2014, 34).

The literature on the uptake of educational technologies, such as the LMS, is increasingly pointing to the important role that the discipline or field plays both in uptake and in application. These studies are beginning to address issues related to the specialised pedagogy that uptake and appropriate use of an LMS might require. The LCT provided the framework within which the affiliation by each department could be studied across faculties; simply put, the affinity between particular disciplinary knowledge structures and LMS uptake.

In the higher education context, we can broadly distinguish between Science, Technology, Engineering and Mathematics (STEM) disciplines and fields, and those that are underpinned by the Humanities, Arts and Social Sciences (HASS).

STEM and HASS disciplines are underpinned by different knowledge forms, different ways of building knowledge, and different understandings of teaching and learning. While most academics understand the requirements of their discipline, they often understand this in a tacit way; LCT can assist researchers and educators to understand the nature of these disciplinary differences in a more explicit way.

LCT comprises five dimensions; this study drew on "specialisation" which provides a way of understanding the relationships between the more technically-oriented STEM disciplines and the more socially-oriented HASS disciplines. Specialisation can be diagrammatically represented as a Cartesian plane, in which the X-axis represents the relative strength and weakness of the social relations (in this case the HASS disciplines); and the Y-axis represents weaker and stronger technical knowledge (in this case STEM knowledge), as in figure 1. 


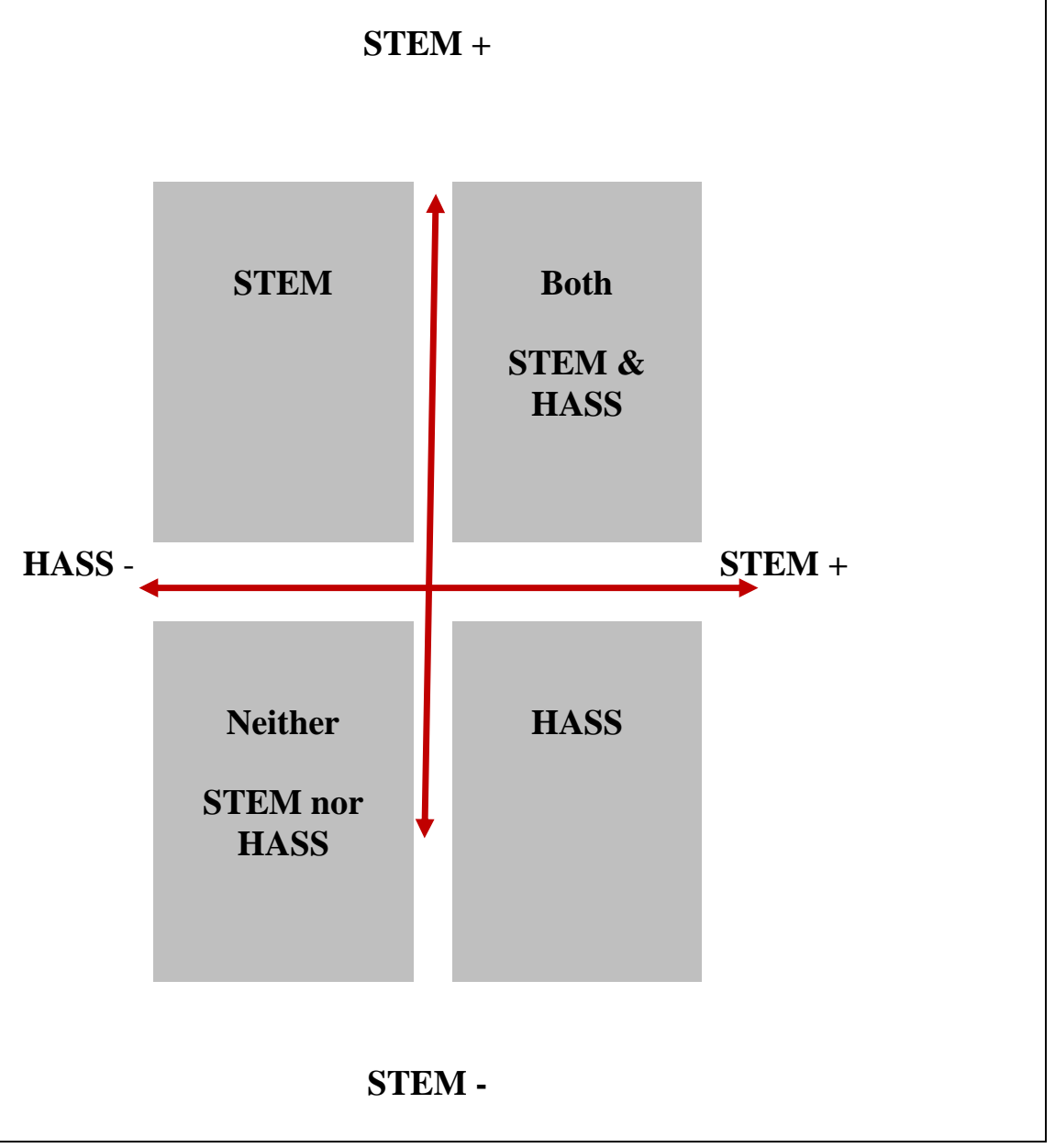

Figure 1: A Specialisation plane for STEM and HASS disciplines (adapted from Maton 2014).

Four quadrants are created within the specialisation plane for STEM and HASS disciplines, dependent on the relative strengths of the STEM and HASS relationships. Where there are weaker HASS and stronger STEM relations, a quadrant is created that foregrounds the STEM disciplines. An example of disciplines with stronger STEM and weaker HASS elements would be the engineering and information technology fields. Where there are stronger HASS and weaker STEM relations, a quadrant is created that foregrounds the HASS disciplines? An example of this quadrant would be more socially-oriented business courses, such as marketing or HR management. In the "plus/plus" quadrant, both STEM and HASS are strong, while in the "minus/minus" 


\section{Shamase}

quadrant neither STEM nor HASS is evident. An example where there is both strong STEM and strong HASS, are the health sciences, which are both technically oriented and people-oriented. The quadrant in which there are low levels of STEM and HASS elements might occur in introductory or generic subjects, but would not be evident across a programme. The concept of disciplinary affinity suggests that as educational technology in the form of the LMS could be considered to be an ICT, this would be more compatible with the STEM disciplines (e.g., engineering fields) or with fields that combined both STEM and HASS disciplines (e.g., the health sciences). Uptake of the LMS would then be expected to be higher in stronger STEM contexts. In contrast, the LMS would be least compatible with the HASS disciplines and subjects in the minus/minus quadrant, and therefore, the uptake of the LMS would be less in such contexts. In this paper, the findings are analysed with a view to locating the programmes at the institution within the specialisation plane and examining the extent to which disciplinary affinity might have played a role in uptake/non-uptake of the LMS.

\section{A Research Design for Investigating Disciplinary Differences}

The present study used the approach of Rhode et al. $(2017,70)$ for research design. The empirical data were collected directly from the LMS database in a cross-sectional process that followed the digital footprint left on the system by each faculty activity, and as a reflection on individual course design. The study was a simple track of the overall LMS usage across faculties essential for information purposes.

Table 1 depicts affiliation by each department across the institution as well as disciplinary characteristics in terms of STEM and HASS. 


\section{Shamase}

Table 1: Active subjects and their disciplinary characteristics

\begin{tabular}{|l|c|c|}
\hline DEPARTMENTS & \% active & Disciplinary characteristics \\
\hline Public Administration & 15 & 1 \\
\hline Economics & 20 & 2 \\
\hline Office Technology & 15 & 2 \\
\hline Marketing & 50 & 1 \\
\hline Human Resources Management & 71 & 3 \\
\hline Accounting & 38 & 1 \\
\hline Law & 21 & 1 \\
\hline Communication & 90 & 3 \\
\hline Chemical Engineering & 90 & 3 \\
\hline Construction Management and QS & 86 & 3 \\
\hline Electrical Engineering & 67 & 3 \\
\hline Mechanical Engineering & 93 & 3 \\
\hline Survey and Civil Engineering & 96 & 2 \\
\hline Agriculture & 23 & 3 \\
\hline Biomedical Sciences & 42 & 3 \\
\hline Chemistry & 12 & 2 \\
\hline Environmental Health & 13 & 3 \\
\hline Info and Comms Technology & 90 & 2 \\
\hline Nature Conservation & 28 & 1 \\
\hline Community Extension & 0 & 3 \\
\hline Mathematics & 91 & \\
\hline
\end{tabular}

$*$ STEM $=3, \mathrm{HASS}=1, \mathrm{BOTH}=2$

The data were then studied, based on the affiliation of subjects to LMS per department. The LMS data show the number of "active" subjects, that is, subjects in which the lecturer has made use of the LMS for teaching and learning. Thus, the data provide two variables: 1) subject LMS activity; and 2) disciplinary characteristics. The departmental information provided insights into the disciplinary characteristics, that is, whether the active subjects are STEM-based, HASS-based or a combination of both STEM and HASS elements. In addition, there was consultation with disciplinary experts who advised on the allocation of values to the STEM and HASS content of the subjects in their programmes. The experts were research consultants who were involved in the research development programme at the university.

The site chosen for this study was a historically disadvantaged institution (HDI) that mainly serves students from disadvantaged socio-economic backgrounds. There were a number of criteria for site selection in this study. Firstly, the university needed to offer 


\section{Shamase}

both HASS and STEM disciplines in order that the disciplinary differences could be compared. The second selection criterion was that the university needed to have a functioning LMS and reasonable connectivity. Thirdly, training and ongoing support for all the academic staff needed to be available. The fourth selection criterion was that while LMS adoption and use had to be encouraged and supported, the choice of whether or not to use the LMS had to be voluntary, with neither institutional incentives nor penalties. The above criteria were intended to facilitate the investigation into the role played by disciplinary differences. Finally, it was important that the institution represented a majority of the previously disadvantaged population, so that the benefits accruing from the research activities and findings would be in service of this community.

\section{Results}

This section measured the levels of LMS activity across faculties using tables, histograms and regression analysis.

The data on the levels of active and inactive subjects on the LMS of departments across faculty were obtained from the LMS data, as shown in table 1 . The table was then expanded to show more detail in terms of their subscription per subject per faculty. Data were entered into MS Excel spread sheets. Columns showing the total number of courses (per department), active courses on LMS and inactive courses on LMS were used. The spread sheet made the computation of percentages on LMS activity per department simpler.

Data were arranged such that faculties were ranked from highest to lowest activities based on LMS activity.

Histograms were used to depict the relationships obtained in tables even further. They showed the varying degrees of LMS activity across departments within the faculty. A correlation analysis was done to determine the level of affinity between characteristics of disciplines with level of activity on LMS.

Finally, regressions were constructed to explain the normal distribution between STEM, HASS and BOTH disciplines across faculties, versus percentage of activity on LMS.

\section{Faculty of Engineering}

The Faculty of Engineering has the most technical disciplines and fields of the three faculties and all programmes are predominantly located in STEM disciplines. The Engineering Faculty data with regard to LMS activity are shown in table 2. 
Shamase

Table 2: Active and inactive courses on LMS in the Faculty of Engineering

\begin{tabular}{|l|c|c|c|c|}
\hline Engineering & $\begin{array}{c}\text { Total no of } \\
\text { courses }\end{array}$ & $\begin{array}{c}\text { Active } \\
\text { courses }\end{array}$ & $\begin{array}{c}\text { Inactive } \\
\text { courses }\end{array}$ & $\begin{array}{c}\text { \%M } \\
\text { LMS } \\
\text { active }\end{array}$ \\
\hline Chemical Engineering & 21 & 19 & 2 & 90 \\
\hline $\begin{array}{l}\text { Construction Management and } \\
\text { Quantity Surveying }\end{array}$ & 21 & 18 & 3 & 86 \\
\hline Electrical Engineering & 54 & 36 & 18 & 67 \\
\hline Mechanical Engineering & 44 & 41 & 3 & 93 \\
\hline Survey and Civil Engineering & 51 & 49 & 2 & 96 \\
\hline Totals & $\mathbf{1 9 1}$ & $\mathbf{1 6 3}$ & $\mathbf{2 8}$ & \\
\hline Averages & $\mathbf{3 8}$ & $\mathbf{3 3}$ & $\mathbf{6}$ & $\mathbf{8 6}$ \\
\hline Max & & $\mathbf{4 9}$ & & $\mathbf{9 6}$ \\
\hline Min & & & & $\mathbf{6 7}$ \\
\hline
\end{tabular}

The Faculty of Engineering had the highest rate of uptake on the LMS, with $67 \%$ to $96 \%$ of subjects active on the LMS across programmes. The "outlier" in the faculty was Electrical Engineering that had both the lowest uptake and the highest rate of inactive subjects. Most departments had 2-3 inactive subjects, which could be explained by the HASS subjects such as communication that were included, or the research projects that require individual supervision by several different supervisors- which often means that the LMS is not used; or work-integrated learning subjects in which students do internships in a range of different workplaces and have both workplace and academic supervisors. Thus, some inactive subjects are expected. However, the Department of Electrical Engineering had a total of 18 inactive subjects, which is cause for concern.

Figure 2 shows that the levels of LMS active subjects in the Faculty of Engineering are relatively even, except for electrical engineering. 


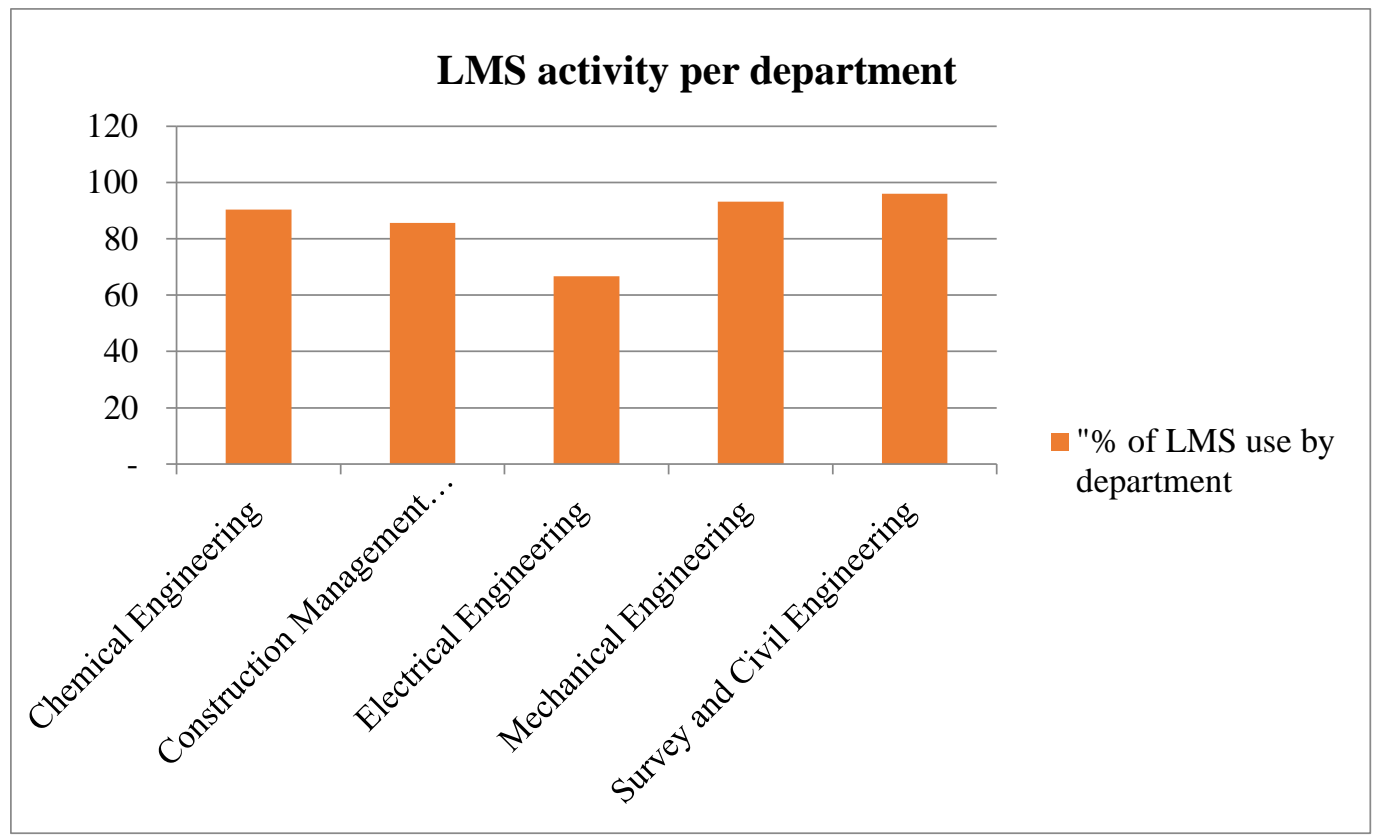

Figure 2: LMS activity per department in the Faculty of Engineering

Figure 2 shows that the Department of Survey and Civil Engineering makes the highest use of the LMS at almost 100\% LMS activity, while the Department of Electrical Engineering is at the lowest, with 65\% LMS activity. The fact that the Department of Electrical Engineering, which is a highly ICT-compatible discipline, had the lowest participation rate on the LMS, is an issue that requires further investigation.

\section{The Faculty of Natural Sciences}

The Faculty of Natural Sciences comprises relatively technical disciplines, but also includes disciplines that contain both STEM and HASS elements, particularly in the Health Sciences.

Table 3 shows the level of activity on the LMS by departments in the Natural Sciences Faculty. 
Shamase

Table 3: Active and inactive courses on the LMS in the Faculty of Natural Sciences

\begin{tabular}{|l|c|c|c|c|}
\hline Faculty of Natural Sciences & Total & Active course & Inactive courses & $\begin{array}{l}\text { \% } \\
\text { LMS } \\
\text { active }\end{array}$ \\
\hline Agriculture & 22 & 5 & 17 & $\mathbf{2 3}$ \\
\hline Biomedical Sciences & 12 & 5 & 7 & $\mathbf{4 2}$ \\
\hline Chemistry & 17 & 2 & 15 & $\mathbf{1 2}$ \\
\hline Environmental Health & 15 & 2 & 13 & $\mathbf{1 3}$ \\
\hline Info and Comms Technology & 50 & 45 & 5 & $\mathbf{9 0}$ \\
\hline Nature Conservation & 18 & 5 & 13 & $\mathbf{2 8}$ \\
\hline Community Extension & 40 & - & 40 & - \\
\hline Mathematics & 22 & 20 & 2 & $\mathbf{9 1}$ \\
\hline TOTALS & $\mathbf{1 9 6}$ & $\mathbf{8 4}$ & $\mathbf{7 2}$ & \\
\hline AVERAGE & $\mathbf{2 5}$ & $\mathbf{1 1}$ & $\mathbf{9}$ & $\mathbf{3 7}$ \\
\hline Max & & & & 91 \\
\hline Min & & & & - \\
\hline
\end{tabular}

The Faculty of Natural Sciences is the second most frequent user of the LMS. The Faculty of Natural Sciences shows an extremely wide range from $0 \%$ to $90 \%$. The Department of Community Extension has no LMS activity, while the Department of Mathematics and the Department of Information and Communications Technology have $90 \%$ of their subjects active on the LMS. There are also high numbers of inactive subjects. On average the inactive subjects range from 13-17 subjects in departments such as Chemistry and Nature Conservation. The "outlier" is the Department of Community Extension with all of its 40 subjects inactive. This could be explained by the important of field work and the high level of people-skills required, but it is a cause for concern that students in this department do not have any opportunities to supplement their learning with online modalities.

Figure 3 graphically represents the very wide range of LMS activity across the faculty. 


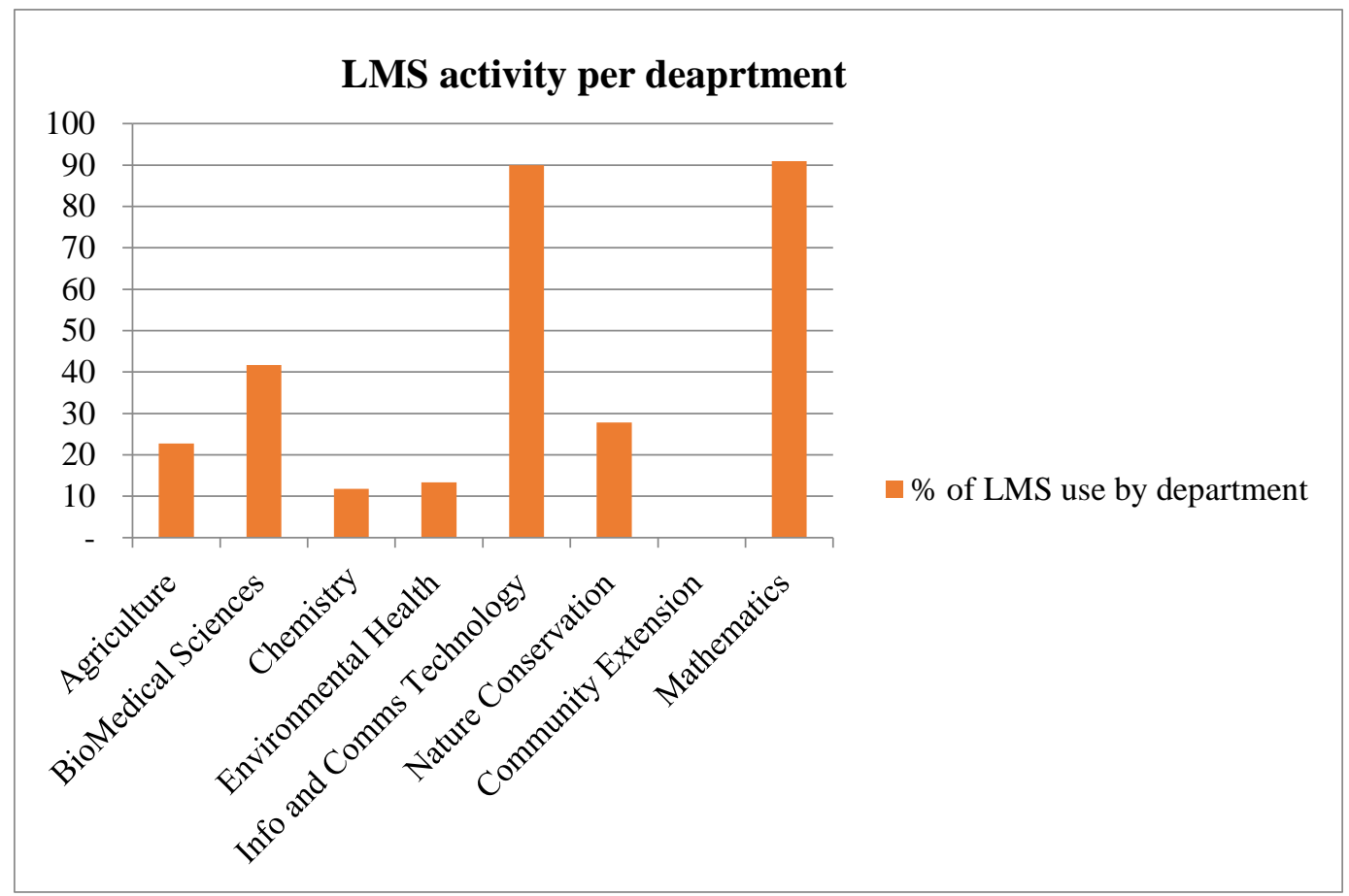

Figure 3: A graph showing lowest to highest LMS activity per department in the Faculty of Natural Sciences

The high level of activity in the Department of Information and Communication Technology was expected, as there is close disciplinary compatibility with LMS. The high level of activity in the Department of Mathematics could also be explained by the high STEM content. While mathematics is a pure discipline, the technical "language" of mathematics makes it compatible with the other more applied STEM disciplines and the technical nature of LMS. The same argument that applied to mathematics, should also apply to the Department of Chemistry, but this department had a relatively low level of activity, as did most of the other departments in the faculty. It is the wide variation that needs further investigation.

\section{Faculty of Management Sciences}

The Faculty of Management Sciences was the lowest ranking faculty with reference to active subjects on LMS. The range of inactive courses per department was from 2-45 subjects, while the range of active courses varied considerably from 3-27 subjects. The "outlier" was communication, with 18 of its 20 courses active. Accounting had 45 of its 72 subjects inactive and only 27 active; as one of the few STEM departments in the faculty it might have been expected that it would have shown more active subjects. 
Table 4: Active and inactive courses on LMS in Faculty of Management Sciences

\begin{tabular}{|c|c|c|c|c|}
\hline $\begin{array}{c}\text { Faculty of Management } \\
\text { Sciences }\end{array}$ & Total courses & $\begin{array}{l}\text { Active } \\
\text { courses }\end{array}$ & $\begin{array}{l}\text { Inactive } \\
\text { courses }\end{array}$ & $\%$ \\
\hline Public Administration & 20 & 3 & 17 & 15 \\
\hline Economics & 20 & 4 & 16 & 20 \\
\hline Office Technology & 13 & 2 & 11 & 15 \\
\hline Marketing & 14 & 7 & 7 & 50 \\
\hline Human Resources Management & 14 & 10 & 4 & 71 \\
\hline Accounting & 72 & 27 & 45 & 38 \\
\hline Law & 14 & 3 & 11 & 21 \\
\hline Communication & 20 & 18 & 2 & 90 \\
\hline Totals & 187 & 74 & 113 & \\
\hline Average & 23 & 9 & & 14 \\
\hline Max & & & & 90 \\
\hline Min & & & & 15 \\
\hline
\end{tabular}

Figure 4 shows the percentage of LMS activity by department in the Faculty of Management Sciences.

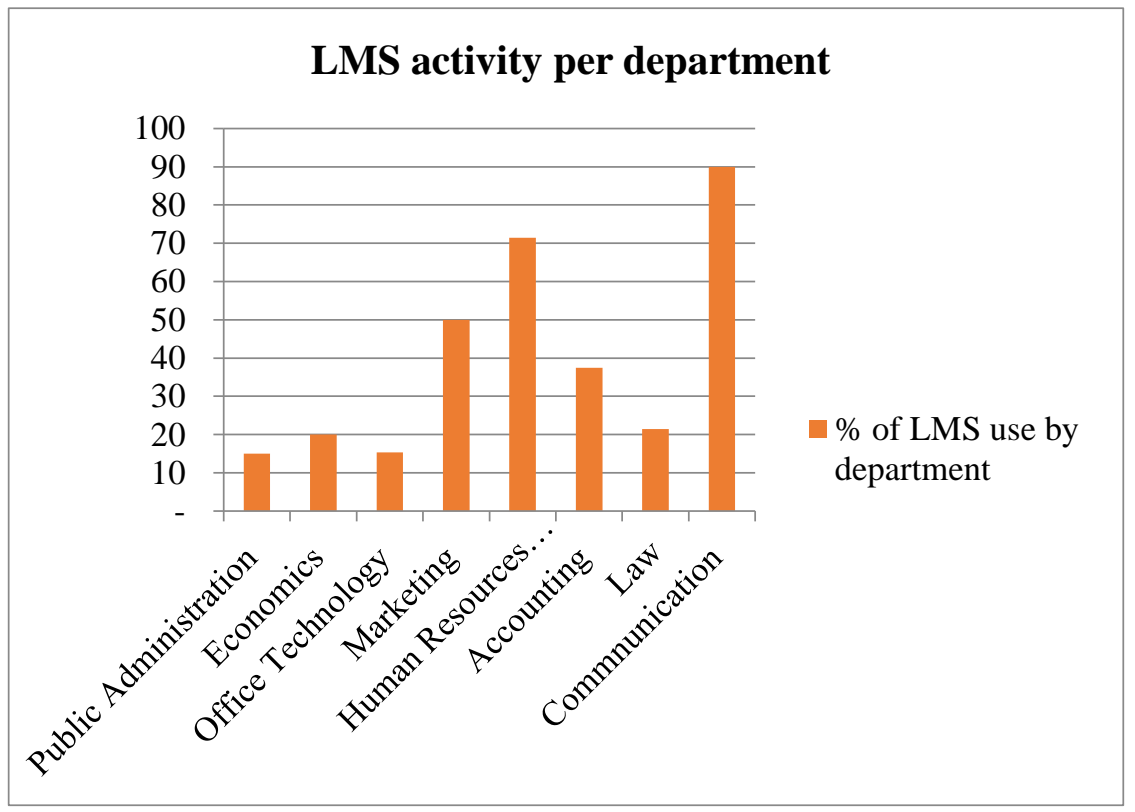

Figure 4: Lowest to highest LMS activity per department in the Faculty of Management Sciences

The Faculty of Management Sciences showed a range of $15 \%$ to $90 \%$ LMS activity across disciplines and ranked the lowest of the three faculties. This was expected as the faculty is largely HASS-based, but what was surprising is that the people-oriented 


\section{Shamase}

programmes such as communication, human resource management and marketing had higher levels of activity than accounting - the only STEM discipline in the faculty.

The Faculty of Management Sciences had a wide range, between 15\%-90\%, of LMS activity from the Department of Public Administration (lowest) to the Department of Communication (highest).

Across the faculties there is evidence that many of the STEM-based departments (e.g., Information and Management Sciences) have high levels of LMS activity, while many of the HASS-based departments (e.g., Public Administration) have low levels of LMS activity. However, this is not as clear-cut as might be expected, as there are departments that are strongly STEM-oriented (e.g., Electrical Engineering and Accountancy) that have low levels of LMS activity, and departments that are HASS-oriented (e.g., Communication and Human Resource Management) that have high levels of LMS activity. It might be expected that the departments that have applied disciplines, such as the engineering disciplines, information and communication technology, might have higher uptake and activity than the "pure" disciplines, such as mathematics. But this was not the case. There was one "pure" discipline, mathematics, with a very high rate of uptake and activity and another "pure" discipline, chemistry, with low uptake. Similarly, there were applied disciplines, such as information and communication technology with high uptake and activity, and an applied discipline, such as office management and technology, with low uptake. These contradictory findings make it necessary to investigate the relationship between LMS uptake and disciplinary differences in greater detail.

\section{Relationship between LMS Active Subjects and Disciplinary Differences}

The second set of findings has to do with the relationship between the uptake of the LMS and the disciplinary nature of the subjects within the various departments. In order to correlate the relationship between the active subjects and the nature of the subjects' discipline, we ascribed a numeric value to each of the disciplines, through consultation with disciplinary experts. Disciplines that were STEM-based were given a value of 3; disciplines that were HASS-based were given a value of 1 ; and disciplines that contained elements of both STEM and HASS (BOTH) were given a value of 2 . Table 5 shows the percentage of active subjects and the disciplinary characteristics of the subjects in numerical values. 


\section{Shamase}

Table 5: Active subjects and their disciplinary characteristics

\begin{tabular}{|l|c|c|}
\hline DEPARTMENTS & \% active & $\begin{array}{c}\text { Disciplinary } \\
\text { characteristics }\end{array}$ \\
\hline Public Administration & 15 & 1 \\
\hline Economics & 20 & 2 \\
\hline Office Technology & 15 & 2 \\
\hline Marketing & 50 & 1 \\
\hline Human Resources Management & 71 & 1 \\
\hline Accounting & 38 & 3 \\
\hline Law & 21 & 1 \\
\hline Communication & 90 & 1 \\
\hline Chemical Engineering & 90 & 3 \\
\hline Construction Management and QS & 86 & 3 \\
\hline Electrical Engineering & 67 & 3 \\
\hline Mechanical Engineering & 93 & 3 \\
\hline Survey and Civil Engineering & 96 & 3 \\
\hline Agriculture & 23 & 2 \\
\hline Biomedical Sciences & 42 & 3 \\
\hline Chemistry & 12 & 3 \\
\hline Environmental Health & 13 & 2 \\
\hline Info and Comms Technology & 90 & 3 \\
\hline Nature Conservation & 28 & 2 \\
\hline Community Extension & 0 & 1 \\
\hline Mathematics & 91 & 3 \\
\hline
\end{tabular}

$*$ STEM $=3$, HASS $=1$, BOTH $=2$

When the percentage of active subjects was correlated with the disciplinary variables, the correlation factor obtained was $\rho=0.4$.

Table 6: Correlation analysis of LMS activity and disciplinary characteristics

\begin{tabular}{|lll|}
\hline & $\%$ active & S/H/B \\
\hline$\%$ active & 1 & \\
S/H/B & 0.431771 & 1 \\
\hline
\end{tabular}




\section{Shamase}

Table 6 shows a positive and significant, but not strong, correlation between LMS activity and disciplinary characteristics. This suggests that the nature of the discipline does impact whether or not the academic teaching the discipline is likely or unlikely to make use of the LMS. As was expected, and as can be seen from the histograms (figures 2, 3, and 4), those disciplines that are more STEM-based tended to have a higher LMS presence, as using the LMS requires a level of technical ability and understanding, thus uptake in these disciplines was higher than in the HASS-oriented disciplines. However, the correlation was not a very strong one, thus it is to be expected that there would be notable exceptions. For example, electrical engineering is a STEM discipline, but has many inactive subjects on the LMS. Conversely, communication, a HASS discipline, had a highly active LMS presence. It is these exceptions that require further investigation.

If one understands the LMS as a technical platform, then the uptake from the STEM disciplines has an obvious explanation. The STEM disciplines are grounded in the use of technology in their fields and in this regard the LMS is a relatively simple technology to use and apply in teaching and learning.

However, if one understands the LMS as a teaching and learning approach, this foregrounds the interpersonal communicative elements of the LMS and provides a possible explanation for why a HASS-oriented department such as the Department of Communications would have so many active subjects on the LMS. Thus, despite the challenges of mastering the system, the interpersonal aspects of the discipline are extremely strong and provide the incentive for this undertaking. Other variables might also need to be taken into account, such as the age of the academic staff, as younger staff tend to be generally more familiar with information and communication technology than older staff (Jonas-Dwyer and Pospisil 2004). The availability of student assistance for the subject could also be a factor that needs to be taken into account, as student assistants can help older academic staff members to become more technologically aware and proficient (Banu and Gandhi 2016). If LMS is understood as part of an educator's "pastoral care" (Price, Richardson, and Jelfs 2007) it would be likely to be used by those who value a caring teaching and learning relationship - which is relatively uncommon in the technical fields and disciplines (Killpack and Melón 2016). A university teacher might make becoming proficient on the LMS a priority, regardless of discipline - particularly in cases when teaching is disrupted and students need to access teaching and learning materials remotely. The availability of IT support from a teaching centre could also play a role in the uptake of the LMS; on a multi-site campus some departments might be better served than others. The ease of use of an online-mediated environment, such as having clear instructions to follow, can also play a role in LMS uptake (Denis et al. 2004; McPherson and Nunes 2004). Thus, if we understand the LMS as a tool for enhancing the teaching and learning relationship, then we might expect that some STEM disciplines, while having no difficulty with the technical aspects, might experience difficulty with the way in which the LMS constructs 


\section{Shamase}

a teaching and learning relationship, which might not be compatible with the "signature pedagogy" (Shulman 2005) of the discipline.

\section{Regressions}

A regression analysis exploring the relationship between LMS activity as a result of disciplinary characteristics was run to determine the confidence level per discipline.

Table 7 presents $\mathbf{f}$ and $\boldsymbol{\theta}$ values from the regression output that explains the confidence level that disciplines are likely to adopt the LMS based on their make-up.

Table 7: Summary of $\mathrm{F}$ and $\theta$ values

\begin{tabular}{|lll|}
\hline & $\mathrm{f}$ & $\theta$ \\
HASS & 20 & 34 \\
BOTH & 52 & 30 \\
STEM & 62 & 27 \\
\hline
\end{tabular}

The f-values explain the confidence level in the probability of LMS uptake in each discipline; while the $\boldsymbol{\theta}$ values represent the standard deviation inferred from the affinity between the LMS and the disciplinary characteristics. The HASS-based disciplines scored the lowest at $20 \%$ probability of LMS uptake, while the BOTH disciplines had a $52 \%$ probability of LMS uptake; that is comparatively moderate, and finally STEMbased disciplines had a $62 \%$ probability of LMS uptake. The second part of the analysis, based on the $\theta$ values, shows that STEM-based disciplines scored the lowest/closest to the make-up of the LMS at $27 \%$, showing a strong affinity. BOTH disciplines were scored at 30\%; with programmes neither pure STEM nor HASS, the make-up is deemed moderately compatible with the LMS. HASS-based disciplines had a 34\% score, the farthest/highest with the least amount of compatibility with the LMS.

Based on the results of the study, academics in the STEM discipline generally find it comfortable to engage and use the LMS for teaching and learning, most likely because of their familiarity with ICTs. In this study, it was not clear whether traditional pedagogies, which are highly content-driven, in the STEM disciplines were supported by the LMS. HASS-based disciplines do not have much compatibility with technical aspects of the LMS; hence the lower uptake of the LMS in these disciplines, but some HASS disciplines could be more compatible with the pedagogies supported by the LMS. Without some assistance it may be difficult for academics in HASS disciplines to learn and use the technology. They might fear the loss of valuable teaching and learning time while they are learning the technology. In such a case, they are likely to refrain from using LMS, and would focus on traditional modes of teaching and learning. Lastly, disciplines that have BOTH STEM and HASS elements, as expected, fell somewhere 
between the two positions. Therefore, LMS activity was higher for those programmes that were closer to STEM disciplines, and lower when they were closer to HASS disciplines. The regression analysis was run to express these relationships graphically. The regressions per discipline are presented below:

\section{HASS-based disciplines (1)}

Figure 5 presents the confidence level in the probability of HASS disciplines to use LMS for teaching and learning based on the disciplinary characteristics.

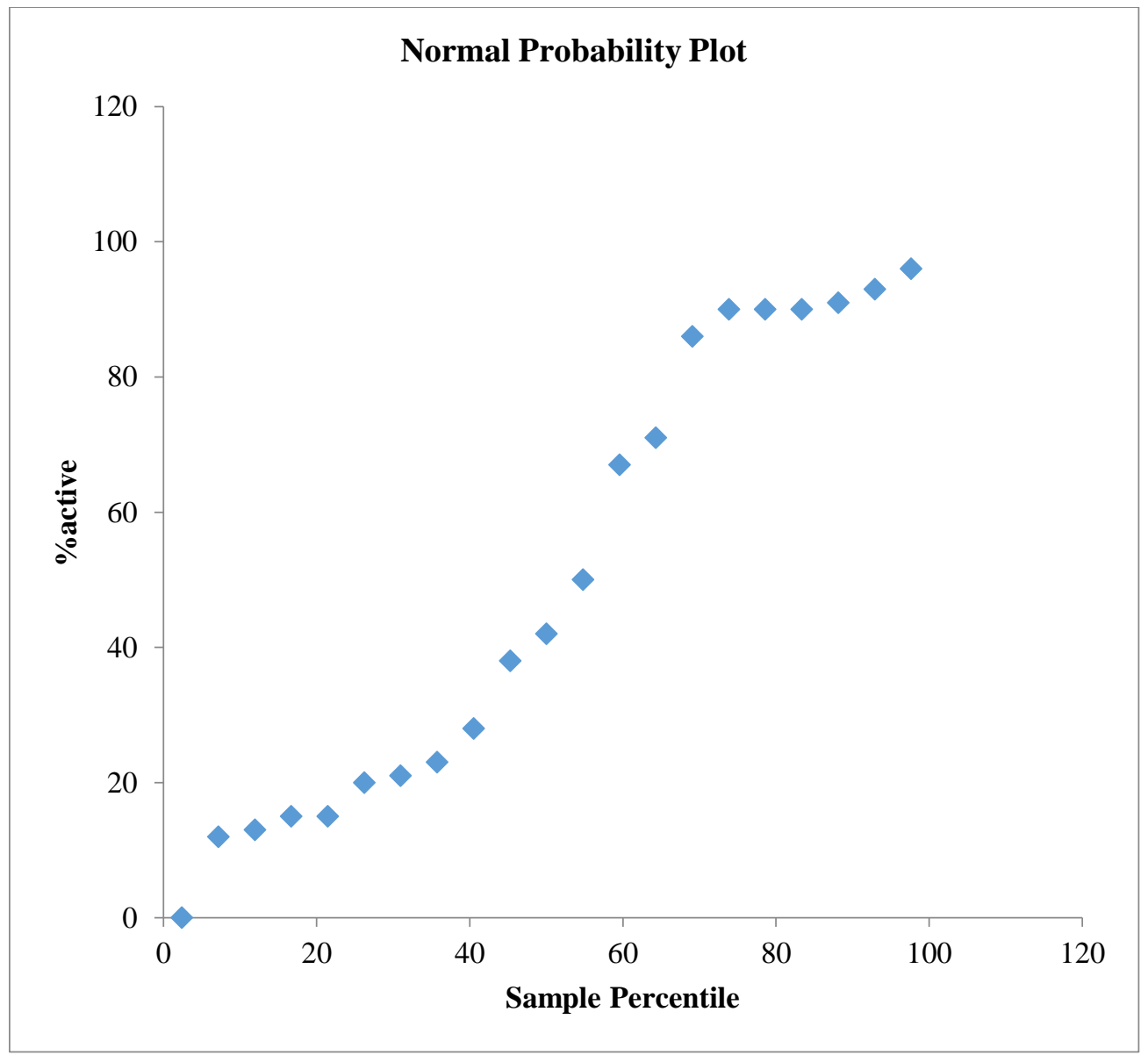

Figure 5: The probability of HASS disciplines to use LMS

BOTH discipline (2)

Figure 6 shows the LMS activity based on disciplinary characteristics and the confidence level in the probability that BOTH disciplines adopt the LMS because of this affinity. 
Shamase

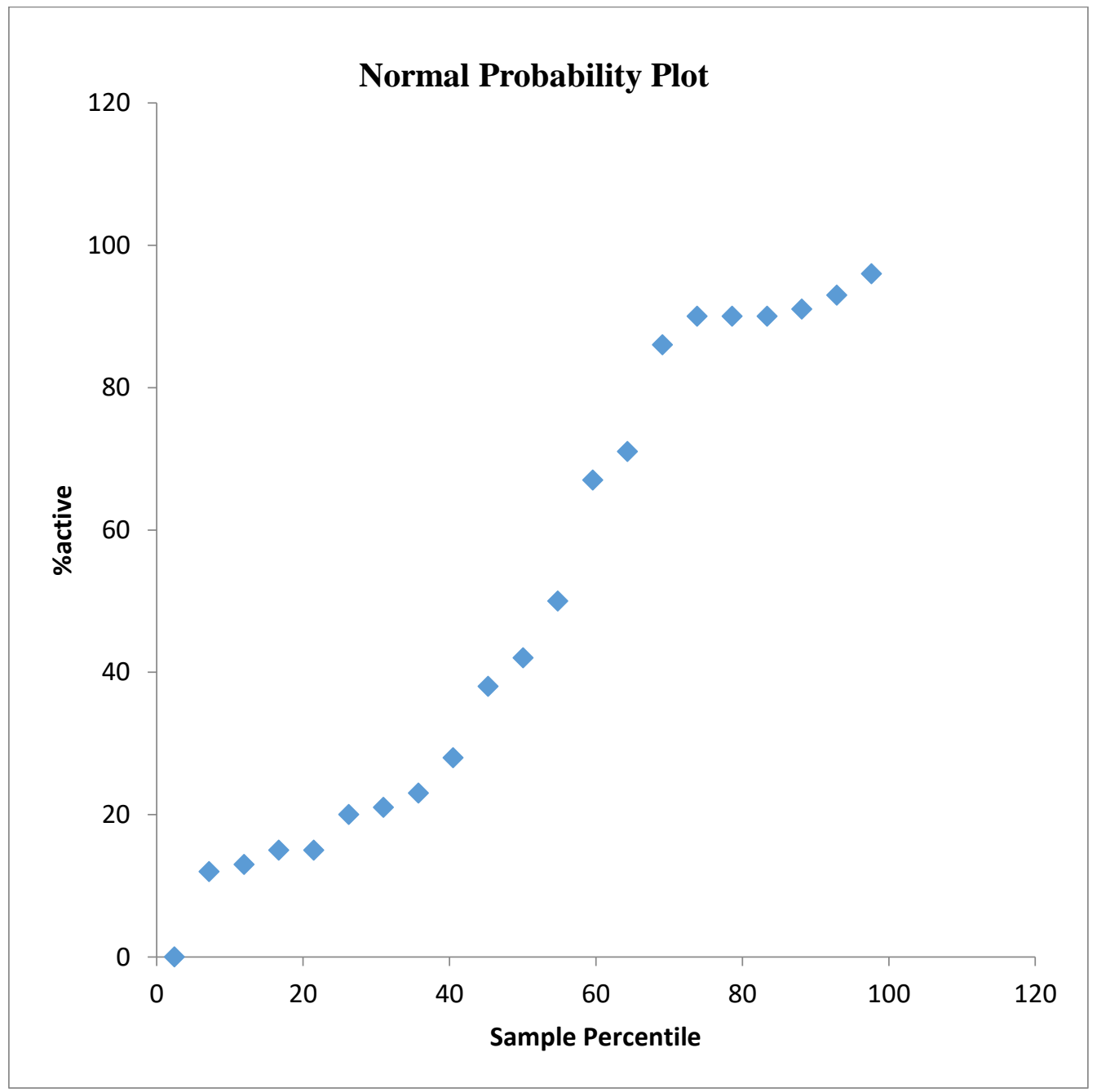

Figure 6: The probability of BOTH disciplines to use LMS

STEM-based disciplines (3)

Figure 7 depicts the level of compatibility between STEM-based disciplinary characteristics and level of LMS activity. 


\section{Normal Probability Plot}

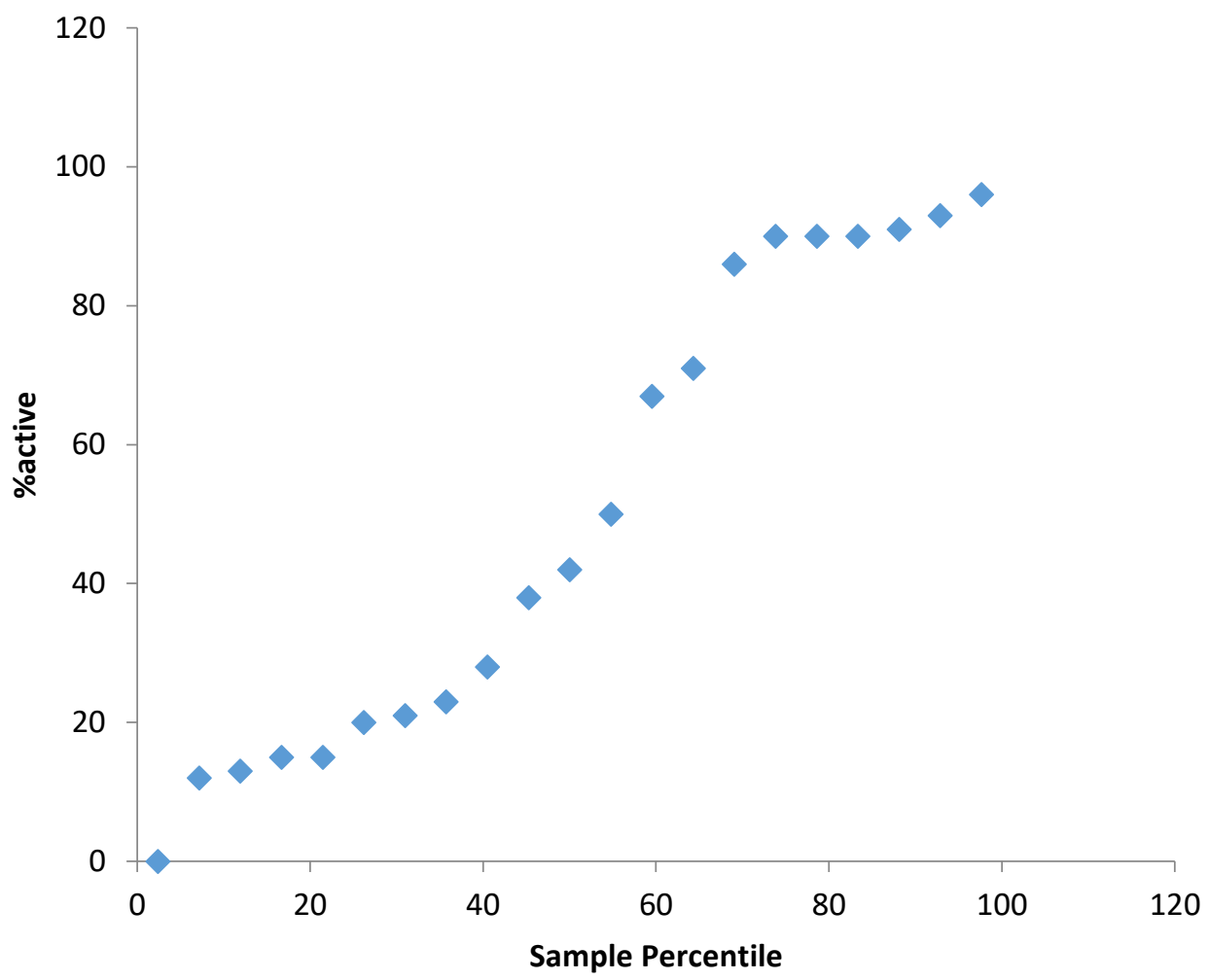

Figure 7: The probability of STEM disciplines to use LMS

\section{Discussion of Findings}

The LCT, as a framework, provided the understanding of knowledge structures within and across faculties. Based on the semantics utilised to delineate the strength of each discipline on the Cartesian plane; the relative strengths of STEM and HASS content explained the ICT compatibility of each discipline.

The determination of this strength is expressed on the specialisation plane in figure 1, with resulting affinities.

Figure 8 shows a depiction of the strength of STEM, HASS and BOTH disciplines across the four quadrants of the plane. 


\section{STEM +}

Quadrant 1

Quadrant 3

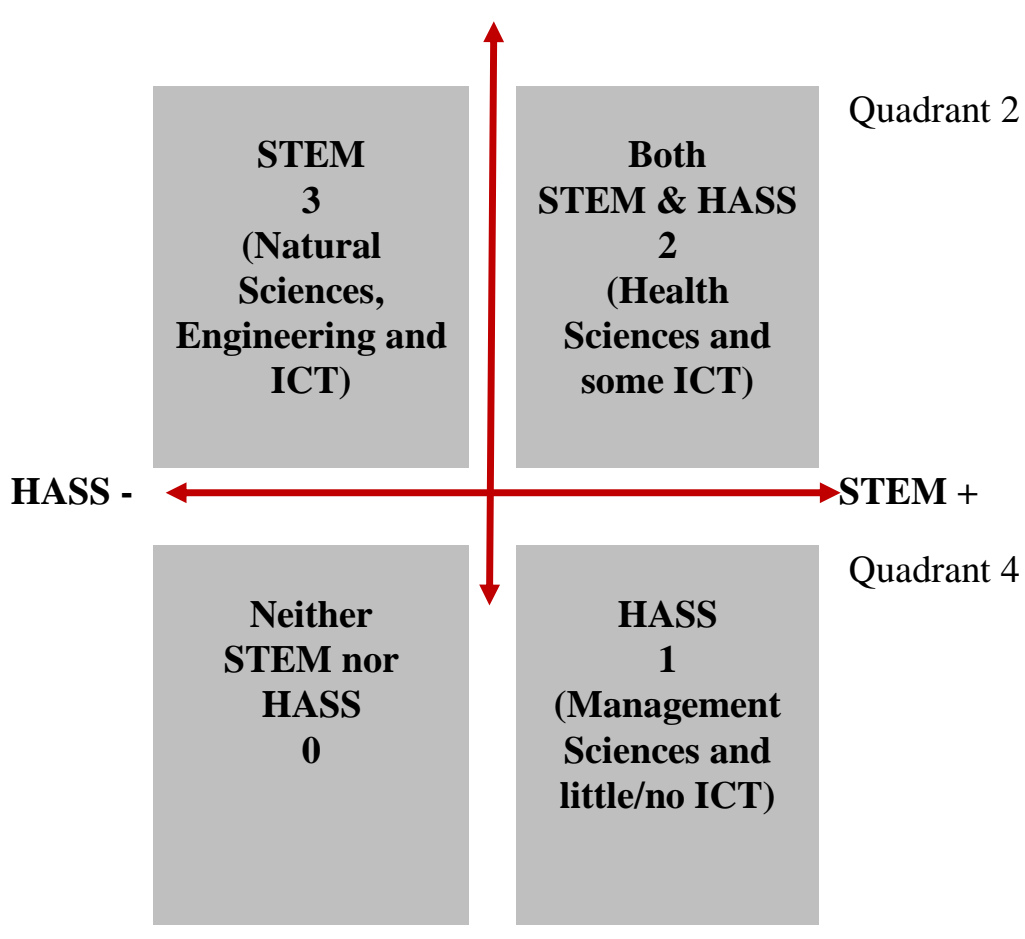

STEM -

Figure 8: A Specialisation Plane showing the results from STEM and HASS disciplines post-analysis

Quadrant 1: shows all pure STEM (3) disciplines in the institution. These include the Faculties of Natural Sciences and Engineering. ICT is also in the Faculties of Natural Sciences. Figures 1 and 5 show the highest and lowest values of subjects active between 0 to $90 \%$ for natural sciences and active between 67-96 in engineering. The subscription tends to be bigger with engineering as compared to natural sciences. The disciplines also had the highest f-values from the F-test. This implies that STEM disciplines are likely to be active on LMS. The SD $(\theta)$ value shows the lowest value among the three, which reinforces the confidence with which the STEM disciplines will use LMS. Quadrant 2: BOTH (2) (combination of STEM and HASS): shows the overlap between two disciplines. BOTH disciplines had a comparatively moderate score for both $\mathrm{f}$-values and $(\theta)$. Quadrant 3: Neither STEM nor HASS: There were no programmes that had neither STEM nor HASS. Thus, this quadrant is not relevant to this study. Quadrant 4: HASS (1): shows pure HASS disciplines. The probability and confidence tests had low and high values respectively. Therefore, the probability of HASS disciplines to be active on LMS is less likely, with the highest confidence value. In the institution these disciplines had the least amount of ICT content. 


\section{Shamase}

The overall correlation analysis between the percentage of active subjects and characteristics had $\rho=0.4$. This proves a statistically significant correlation between the two variables, meaning the disciplinary characteristics can have an influence on the uptake of LMS by faculties.

The hypothesis of the study was that disciplinary characteristics do not have any influence on the subscription of subjects to LMS. Therefore, the hypothesis is rejected.

\section{Conclusion}

The study design was transverse, which limited the time over which the study was conducted; however, valuable assertions were established by the study. At the institution the use of LMS varied across faculties due to differences in disciplinary characteristics. The affinities across HASS-based, STEM-based and BOTH STEM and HASS disciplines influenced academics' uptake of the LMS for teaching and learning relative strengths and weaknesses of STEM and HASS across the institution.

The main findings of the study can be summarised as follows:

- Finding 1: Compatibility of LMS activity with disciplinary characteristics.

- Inference 1: The Faculty of Engineering is mostly STEM-based and the STEM-based disciplines in the faculty displayed the highest LMS activity, confirming compatibility with the technical nature of the programmes in the faculty.

- Finding 2: Disparities in the rate of adoption within disciplines.

○ Inference 2: All STEM-based, HASS-based and BOTH disciplines had outliers. Disparities occurred in the manner that certain programmes displayed unexpectedly high activity on LMS, while some were unexpectedly low (including one with no activity at all). The patterns of LMS activity depict the apparent reluctance to take up and use of LMS evenly across and within disciplines.

The findings, especially with regard to the outliers, require further research and investigation. Detailed follow-up studies will be necessary to determine the causes of the unexpected higher and lower levels of uptake. These causes might be related to specific disciplinary features; technical features (such as the functionality of the LMS at remote other features); and the availability or non-availability of additional support for LMS users who experience challenges with the basic technology. The literature points to a number of additional possible causes, such as academic staff perceptions, expectations, age and attitude of academics across disciplines. Furthermore, incentives and penalties, as well as institutional readiness according to institutional goals need further investigation in future studies. 


\section{Shamase}

The contribution that this study makes is the significant role that the nature of the academic's home discipline plays in the uptake of an LMS. This understanding should assist e-learning centres and facilitators in planning their work more carefully around supporting academic staff, especially in the HASS disciplines, as these academics are more likely to experience difficulty. The study will also help HASS academics to understand issues of disciplinary "disconnections" between their disciplines and LMS, and how to address these challenges.

\section{References}

Alias Nor Aziah, and Ahmad Marzuki Zainuddin. 2005. "Innovation for better Teaching and Learning: Adopting the Learning Management System." Malaysian Online Journal of Instructional Technology 2 (2): 27-40. www.semanticscholar.org.

Angeli, Charoula, and Nicos Valanides. 2009. "Epistemological and Methodological Issues for the Conceptualization, Development and Assessment of ICT-TPCK: Advances in Technological Pedagogical Content Knowledge (TPCK)." Computers and Education 52: 154-168. citeseerx.ist.psu.edu. https://doi.org/10.1016/j.compedu.2008.07.006.

Banu, M. M. A. F., and S. M. G. Gandhi. "Will Computers Replace Conventional Teachers and Teaching Methods?" Global English-Oriented Research Journal 2 (2): 9-14.

Bousbahi, Fatiha, and Muna Saleh Alrazgan. 2015. "Investigating IT Faculty Resistance to Learning Management System Adoption Using Latent Variables in an Acceptance Technology Model.” The Scientific World Journal. Article ID 375651. https://doi.org/10.1155/2015/375651.

Campbell, P. John, P. DeBlois, and Diana Oblinger. 2007. "Analytic: A New Tool for a New Era. EDUCAUSE Review 42 (4): 40-57. er.educause.edu.

Chai Sing Chai, Joyce Hwee Ling Koh, and Chin-Chung Tsai. 2010. "Facilitation Preservice Teachers' Development of Technological, Pedagogical, and Content Knowledge (TPACK)." Educational Technology and Society 13 (4): 63-73. www.semanticscholar.org.

Conole, Grainne, and Martin Dyke. 2004. "What are the Affordances of Information and Communication Technologies? AlT-J.” Research in Learning Technology 12 (2): 113124. https://doi.org/10.1080/0968776042000216183.

Day, David, and Margaret Lloyd. 2007. "Affordances of Online Technologies: More than the Properties of the Technology.” Australian Educational Computing 22 (2): 17-21. eprint.qut.edu.au.

Denis, Brigitte, Philip Watland, Sebastien Pirotte, and Nathalie Verday. 2004. "Roles and Competencies of the E-tutor." In Networked Learning 2004: A Research-based Conference on Networked Learning and Lifelong Learning: Proceedings of the Fourth International Conference, Lancaster, 150-157. 


\section{Shamase}

Dintoe, Seitabeleng Susan. 2018. "Educational Technology Adopters: A Case Study in University of Botswana." International Journal of Education and Development using Information and Communication Technology (IJEDICT) 14 (1): 52-90. Files.eric.ed.gov.

Fathema, Nafsaniath, and Kyra Leigh Sutton. 2013. "Factors Influencing Faculty Members' Learning Management Systems Adoption Behavior Analysis Using the Technology Acceptance Model." J-Gate and Academic Journal Database 2 (4): 20-28. www.researchgate.net.

Fathema, Nafsaniath, David Shannon, and Margaret Ross. 2015. "Expanding the Technology Acceptance Model (TAM) to Examine Faculty Use of Learning Management Systems (LMSs) in Higher Education Institutions." Journal of Online Learning and Teaching 11 (2): 210-232. www.researchgate.net.

Fresen, Jill W. 2011. "Factors Influencing Lecturer Uptake of E-learning." Teaching English with Technology 11 (1): 81-97. Files.eric.ed.gov.

Gautreau, Cynthia S. 2011. "Motivational Factors Affecting the Integration of a Learning Management System by Faculty”. The Journal of Educators Online 8 (1): 1-25. https://doi.org/10.9743/JEO.2011.1.2. Corpus ID: 9373349.

Howard, Sarah K., and Karl Maton. 2011. "Theorising Knowledge Practices: A Missing Piece of the Educational Technology Puzzle.” Research in Learning Technology 19 (3): 191206. www.researchgate.net. https://doi.org/10.3402/rlt.v19i3.17109.

Jonas-Dwyer, Diana, and Romana Pospisil. 2004. “The Millennial Effect: Implications for Academic Development." In Proceedings of the 2004 Annual International Conference of the Higher Education Research and Development Society of Australasia (HERDSA), 356366.

Killpack, Tess L., and Laverne C. Melón. 2016. "Toward Inclusive STEM Classrooms: What Personal Role Do Faculty Play?” CBE - Life Sciences Education 15 (3): es3. https://doi.org/10.1187/cbe.16-01-0020.

King, Emma, and Russel Boyatt. 2015. "Exploring Factors that Influence Adoption of Elearning within Higher Education." British Journal of Educational Technology 46 (6): 1272-1280. https://doi.org/10.1111/bjet.12195.

Koehler, Mathew J., and Punya Mishra. 2005. "What Happens when Teachers Design Educational Technology? The Development of Technological Pedagogical Content Knowledge.” Journal of Educational Computing Research 32 (2):131-152. https://doi.org/10.2190/OEW7-01WB-BKHL-QDYV.

Koehler, Mathew J., and Punya Mishra. 2009. "What is Technological Pedagogical Content Knowledge?" Contemporary Issues in Technology and Teacher Education 9 (1): 60-70. https://www.researchgate.net/publication/241616400. https://doi.org/10.2190/0EW701WB-BKHL-QDYV. 


\section{Shamase}

Maton, Karl. 2014. “A TALL Order? Legitimate Code Theory for Academic Language and Learning." Journal of Academic Language and Learning 9 (3): A34-A48.

Journal.aall.org.au.

McPherson, Maggie A., and Jose Miguel B. Nunes. 2004. "The Role of Tutors as an Integral Part of Online Learning Support.” European Journal of Open and Distance Learning.

Oliver, Ron. 2002. "The Role of ICT in Higher Education for the 21st Century: ICT as a Change Agent for Education.” Accessed April 14, 2007. Bhs-ict.pbworks.com.

Pajo, Karl, and Catherine Wallace. 2001. "Barriers to the Uptake of Web-based Technology by University Teachers." International Journal of Learning and Distance Learning 16 (1): 70-84. eric.ed.gov.

Price, Linda, John T. E. Richardson, and Anne Jelfs. 2007. "Face-to-face versus Online Tutoring Support in Distance Education.” Studies in Higher Education 32 (1): 1-20. https://doi.org/10.1080/03075070601004366.

Rhode, Jason, Stephanie Richter, Peter Gowen, Tracy Miller, and Cameron Wills. 2017. "Understanding Faculty Use of the Learning Management System." Online Learning 21 (3): 68-86. Files.eric.ed.gov. https://doi.org/10.24059/olj.v21i3.1217.

Shulman, Lee S. 2005. “Pedagogies.” Liberal Education 91 (2): 18-25.

Van Barneveld, Angela, Kimberly E. Arnold, and John P Campbell. 2012. "Analytics in Higher Education: Establishing a Common Language." EDUCAUSE Learning Initiative 1 (1): I-II. Er.educause.edu.

Wichadee, Saovapa. 2015. 'Factors related to Faculty Members' Attitude and Adoption of a Learning Management System." The Turkish Online Journal of Educational Technology 14 (4): 53-61. files.eric.ed.gov.

Winn, William. 2002. "Research into Practice: Current Trends in Educational Technology Research: The Study of Learning Environment." Educational Psychology Review 14 (3): 331-51. https://doi.org/10.1023/A:1016068530070. 